CLINICAL STUDY

\title{
Muscle strength in elderly adults with GH deficiency after 10 years of $\mathrm{GH}$ replacement
}

Galina Götherström, Mariam Elbornsson, Katharina Stibrant-Sunnerhagen ${ }^{1}$, Bengt-Åke Bengtsson, Gudmundur Johannsson and Johan Svensson

Research Centre for Endocrinology and Metabolism, Sahlgrenska University Hospital, Gröna Stråket 8, SE-41345 Göteborg, Sweden and ${ }^{1}$ Research Group for Rehabilitation Medicine, Institute of Neuroscience and Physiology, Göteborg University, SE-41345 Göteborg, Sweden

(Correspondence should be addressed to G Götherström; Email: galina.gotherstrom@gu.se)

\begin{abstract}
Context: Only few studies have investigated the effects of GH replacement on muscle strength in elderly patients with GH deficiency (GHD).

Objective, design, and patients: In this prospective open-labeled study, the effects of 10 years of GH replacement on muscle strength and neuromuscular function were followed in 24 elderly GHD adults (mean age of 65.2 years; range 61-74 years). Muscle strength was compared with reference values obtained from the background population.

Results: The mean initial GH dose of $0.72 \mathrm{mg} /$ day was lowered to $0.37 \mathrm{mg} /$ day. The mean IGF1 SDS increased from -1.10 at baseline to 1.17 at study end. GH replacement induced a sustained increase in lean body mass and a transient increase in isometric knee flexor strength. Isometric knee extensor strength was reduced after 10 years. However, after correction for age and gender, using observed/predicted value ratios, there was sustained and even progressive increase in most variables reflecting muscle strength. Measurements of neuromuscular function showed unchanged voluntary motor unit activation after 10 years.

Conclusions: Ten years of GH replacement therapy in elderly GHD adults resulted in a transient increase in isometric knee flexor strength, and provided protection from most of the normal age-related decline in muscle performance and neuromuscular function.
\end{abstract}

European Journal of Endocrinology 163 207-215

\section{Introduction}

GH secretion declines with increasing age. Although elderly adults with GH deficiency (GHD) have significantly lower GH secretion than normal elderly subjects (1), both normal aging (2) and $\operatorname{GHD}(3,4)$ are associated with decreased muscle mass and strength. As GH plays an important role in maintaining of body composition, the progressive decline in GH secretion with increasing age may contribute to the age-related impairments in muscle mass and function (5). In normal elderly subjects, sarcopenia is followed by adverse consequences such as disability and loss of independent way of living. Impaired muscle strength has been reported to be highly predictive of all-cause mortality in advanced age (6).

The results of several studies suggest that the reduced muscle strength in young GHD adults can be reversed by GH replacement $(3,7-10)$. However, absolute values of muscle strength returned towards baseline values between 5 and 10 years of GH replacement in GHD adults of various ages in one study (10).

We demonstrated that GHD adults above 60 years of age had decreased age- and sex-adjusted muscle strength (4). The 5 years of GH replacement therapy normalized age- and sex-adjusted values of knee flexor strength, whereas knee extensor and handgrip strength were not fully normalized in the elderly GHD patients (4). To date, the effects of prolonged ( $>5$ years) $\mathrm{GH}$ replacement on muscle strength in elderly GHD adults are unknown.

In this prospective, open-labeled, single-center study, the effect of 10-year GH replacement on muscle strength was determined in 24 adults with GHD above 60 years of age with adult onset pituitary disease. In addition, superimposed single-twitch electrical stimulations were performed in the elderly patients with GHD to estimate neuromuscular function and motor unit activation.

\section{Patients and methods}

Twenty-four (13 women) hypopituitary patients above 60 years of age with adult onset GHD and with a mean age of 65.2 (3.4; range 61-74) years were included in 1991-1995. All the patients had known pituitary 
disease. The pituitary deficiency was mainly caused by pituitary tumors or their treatment (Table 1). Twenty patients had been treated surgically, and five of the patients had received radiotherapy. Most patients had multiple anterior pituitary deficiencies (Table 1). Possibly due to the late effects of radiotherapy, several patients had more anterior pituitary deficiencies at study end as compared with baseline (Table 1). In 22 patients, the diagnosis of GHD was based on a maximum peak $\mathrm{GH}$ response of $<3 \mu \mathrm{g} / \mathrm{l}$ during insulin-induced hypoglycemia (blood glucose $\leq 2.2 \mathrm{mmol} / \mathrm{l}$ ) or during a combined GHRH-pyridostigmine stimulation test $(n=1)$. In two patients with three additional anterior pituitary hormonal deficiencies, the diagnosis was based on low serum concentration of insulin-like growth factor 1 (IGF1) and/or measurements of 24-h GH secretion. When required, patients received replacement therapy with glucocorticoids, thyroid hormone, gonadal steroids, and desmopressin throughout the study period. Of the 13 women, 4 received estrogen replacement therapy.

Three patients died during the study period (multiple cerebrovascular lesions $(n=1)$, pneumonia $(n=1)$, and myocardial infarction $(n=1))$. Three patients discontinued from the study due to adverse events (prostatic cancer $(n=1)$ and epileptic seizures $(n=2)$ ) and one patient due to lack of compliance. All patients were, however, retained in the statistical analysis since the last observed value for each variable was carried forward according to the intention-to-treat approach used.

\section{Study protocol}

This is an ongoing, prospective, open-label treatment trial of the administration of recombinant human GH in adult patients with GHD. Twenty-four consecutive elderly patients with adult onset GHD were treated for 10 years with $\mathrm{GH}$. The initial target dose of $\mathrm{GH}$ in the first 12 patients was $11.9 \mu \mathrm{g} / \mathrm{kg}$ per day. The dose was gradually lowered and individualized when the weightbased dose regimen was abandoned (11). In the remaining 12 patients, the $\mathrm{GH}$ dose was individualized from the beginning. The individualization of the dose of GH was performed with the aim of normalizing IGF1 SDS and body composition in each patient (11).

At baseline and after each year of treatment, physical examinations including measurements of body composition and muscle strength were performed. Titration of the dose of GH was performed every third month during the first year and every sixth month thereafter. Body weight was measured in the morning to the nearest $0.1 \mathrm{~kg}$, and body height was measured barefoot to the nearest $0.01 \mathrm{~m}$. The body mass index (BMI) was calculated as body weight in kilograms divided by height in meters squared.

\section{Ethical considerations}

Informed consent was obtained from all patients. The study was approved by the Ethics Committee at the University of Göteborg and the Swedish Medical Products Agency (Uppsala, Sweden).

\section{Body composition}

Dual-energy X-ray absorptiometry (DEXA; Lunar DPX-L, Lunar Corporation, Madison, WI, USA) was used to measure lean body mass $(\mathrm{LBM})$ and body fat $\left(\mathrm{BF}_{\mathrm{DEXA}}\right)$ (12). Software versions were changed several times (from 1.1 to lastly 1.35 ) during the study, but the version 1.33 was generally used for a large period of the study. A phantom (BONA SIDE, Ltd 313, West Beltline HWY, Madison, WI, USA) was frequently

Table 1 Causes of pituitary deficiency and the type of pituitary deficiency in the study population of 24 elderly patients above 60 years of age with adult onset GH deficiency (GHD). No patient had isolated GHD.

\begin{tabular}{|c|c|c|c|c|c|c|}
\hline & & \multicolumn{2}{|c|}{ Men } & \multicolumn{2}{|c|}{ Women } & Total \\
\hline \multicolumn{2}{|c|}{ Non-secreting pituitary adenoma } & \multicolumn{2}{|c|}{7} & \multicolumn{2}{|c|}{8} & 15 \\
\hline Hormone-secreting & adenoma & \multicolumn{2}{|c|}{2} & \multicolumn{2}{|c|}{3} & 5 \\
\hline Craniopharyngioma & & \multicolumn{2}{|c|}{1} & \multicolumn{2}{|c|}{1} & 2 \\
\hline \multicolumn{2}{|l|}{ Empty sella } & \multicolumn{2}{|c|}{1} & \multicolumn{2}{|c|}{1} & 2 \\
\hline \multirow[b]{2}{*}{$\begin{array}{l}\text { Number of } \\
\text { deficiencies }\end{array}$} & \multicolumn{3}{|c|}{ Baseline } & \multicolumn{3}{|c|}{ Study end } \\
\hline & Men & Women & Total & Men & Women & Total \\
\hline $\begin{array}{c}\text { One additional } \\
\text { deficiency }\end{array}$ & 2 & 3 & 5 & 1 & 2 & 3 \\
\hline $\begin{array}{l}\text { Two additional } \\
\text { deficiencies }\end{array}$ & 1 & 3 & 4 & 2 & 3 & 5 \\
\hline $\begin{array}{l}\text { Three additional } \\
\text { deficiencies }\end{array}$ & 8 & 7 & 15 & 8 & 8 & 16 \\
\hline Diabetes insipidus & 1 & 2 & 3 & 2 & 2 & 4 \\
\hline
\end{tabular}


used for calibration purposes. The relative error for LBM was $1.5 \%$.

Body cell mass (BCM) and BF were estimated using a four-compartment model based on total body potassium (TBK) and total body water (TBW) assessments (13). TBK was assessed using a whole body counter (coefficient of variation $(\mathrm{CV})=2.2 \%$ ), and TBW was determined by the isotope dilution of tritiated water $(\mathrm{CV}=3.2 \%)$.

Total body nitrogen was measured by in vivo neutron activation with a measurement error of approximately $\pm 4 \%(14,15)$.

\section{Measurements of muscle function}

Isometric knee extensor and knee flexor strength at knee angles of $60^{\circ}(\pi / 3 \mathrm{rad})$, and isokinetic concentric muscle strength at angular velocities of $60 \%$ $(\pi / 3 \mathrm{rad} / \mathrm{s})$ and $180^{\circ} / \mathrm{s}(\pi \mathrm{rad} / \mathrm{s})$ were measured using a Kin-Com dynamometer (Chattecx Co., Chattanooga, TN, USA) (16). Gravity correction was used for isokinetic muscle strength (16). The patients were positioned sitting in the test chair with a hip angle of $90^{\circ}(\pi / 2 \mathrm{rad})$. The knee-joint axis was approximated to the Kin-Com measuring axis. The lower leg was secured to the Kin-Com shin pad at $3 \mathrm{~cm}$ proximal to the insertion of the anterior tibialis muscle with the ankle joint at $90^{\circ}$. The trunk, hip, and thigh were strapped down to avoid involuntary movements. Warming-up submaximal exercise was performed on a bicycle ergometer for $5 \mathrm{~min}$ prior to the muscle tests. The methodological errors in duplicate measurements for isometric muscle strength and isokinetic muscle strength at angular velocities of 60 and $180 \%$ s were 9, 8 , and $8 \%$ respectively (16).

Right and left handgrip strength was measured using an electronic grip force instrument (Grippit, AB Detector, Göteborg, Sweden) that measures the maximum momentary force and the mean force over a set period of $10 \mathrm{~s}$ in Newtons. The methodological error between duplicate determinations was between 4.4 and 9.1\% (17).

Local muscle endurance in the quadriceps muscle was measured as the percentage reduction (fatigue index) in peak torque between the first and the last three knee extensions in a series of 50 maximal voluntary concentric contractions with an angle of velocity of $180^{\circ} / \mathrm{s}(\pi \mathrm{rad} / \mathrm{s})$. The methodological error was $1.4 \%$ from duplicate determinations (18).

During isometric muscle contractions, superimposed single-twitch electrical stimulation was given through the percutaneous stimulation of the quadriceps muscle, as described by Rutherford et al. (19) and Thomeé et al. (20), to estimate the degree of activation of motor units at maximal voluntary contraction. An electrical stimulator monitored by a PC software program (AB Detector) was used, connected to five $10-\mathrm{cm}$ electrodes placed over the vastus medialis and rectus femoris muscles (20). Two stimuli, square wave pulses, $0.1 \mathrm{~s}$ in duration, were used, with $1 \mathrm{~s}$ between each twitch. With the muscles relaxed, the stimuli were first given at increasing voltages up to the maximal stimulation effect, usually obtained at around $150 \mathrm{~V}$. The maximal level of stimulation was then used by superimposing twitches on $\sim 30,50,70$, and $100 \%$ of maximal voluntary isometric activation for $4 \mathrm{~s}$, with an interval of about $1 \mathrm{~min}$ between each level. The subjects were asked to keep to the various activation levels as closely as possible by matching the effect according to the level indicated on the screen. Extrapolations from linear regression analyses were made using the additional torque from the superimposed twitches as a dependent variable to calculate any possible additional torque at true maximal isometric contraction (20).

\section{Muscle strength values from a normal population}

In 1994 and 1995, 144 men and women, aged 40-79 years, selected at random from the population census of the city of Göteborg, were invited to participate in a study measuring muscle function (2). A physical examination was performed to exclude any orthopedic problems, neurological deficits, and hypertension (2). At least, 1 person of each age was tested (2). The subjects formed 10-year cohorts, such as 40-49, 50-59, 60-69, and 70-79 years, for each sex. The numbers of men/women tested were 16/19, 20/15, 18/27, and $15 / 14$ with increasing age (2).

The research unit that performed these measurements in the background population was the same one that measured muscle function in the elderly adults with GHD. Comparisons with the reference population were made by applying a predicted value for muscle function for each GH-deficient patient. The predicted value was obtained by calculating a mean value for each muscle test in each 10-year cohort of men and women in the reference population (in the present study, only the 60-69 and 70-79 year intervals were relevant). The observed/predicted percentages for each patient were then calculated. Mean body height (1.69 (s.E.M. $0.02) \mathrm{m}$ ), mean body weight (74.0 (s.E.M. 2.5) kg), and mean BMI $(25.9$ (s.E.M. 0.8$\left.) \mathrm{kg} / \mathrm{m}^{2}\right)$ in the reference population were similar as in the present study population.

\section{Biochemical assays}

Serum IGF1 concentration was determined by an RIA after $\mathrm{HCl} /$ ethanol precipitation of binding proteins (Nichols Institute Diagnostics, San Juan Capistrano, CA, USA). Inter-assay and intra-assay CV were 5.4 and $6.9 \%$ respectively at a mean serum IGF1 concentration of $126 \mu \mathrm{g} / \mathrm{l}$, and 4.6 and $4.7 \%$ respectively at a mean serum IGF1 concentration of $327 \mu \mathrm{g} / \mathrm{l}$. The detection 
limit of the assay was $13.5 \mu \mathrm{g} / \mathrm{l}$. The individual serum IGF1 values were compared with age- and sex-adjusted values obtained from a reference population of 197 men and 195 women (21). The individual IGF1 SDS could then be calculated as described previously (22).

\section{Statistical methods}

All the descriptive statistical results are presented as the mean (S.D). For all variables, within-group differences were calculated using a one-way ANOVA, with all data obtained from all time points, and with time as the independent variable. Post-hoc analysis was performed using Student-Newman-Keuls test. Between-group differences (men versus women) were calculated by a one-way ANOVA, with all data obtained from all time points, and with gender as the independent variable. In order to eliminate for baseline differences, data were transformed as percentage change or change from baseline before the analyses of between-group differences.

All analyses were performed using an intentionto-treat approach (based on the last observation carried forward principle). Correlations were calculated using Pearson's linear regression coefficient. A two-tailed $P \leq 0.05$ was considered significant.

\section{Results}

\section{GH dose, IGF1 SDS, and body composition}

The mean GH dose was gradually lowered. The mean IGF1 SDS increased from -1.10 at baseline to 1.17 at study end (Table 2). Body weight and body height decreased, while BMI was unchanged. There was a sustained reduction in $\mathrm{BF}$, and a sustained increase in LBM, as measured using DEXA. Using the fourcompartment model, BF was reduced, whereas BCM was unchanged at study end.

\section{Muscle strength (absolute values)}

There was an initial increase in isometric knee flexor strength with maximum values between 3 and 5 years, followed by a decline and a return to the baseline level (Table 3). Concentric knee flexor strength (60 and $180 \%$ s) and concentric knee extensor strength (60 and $180^{\circ} / \mathrm{s}$ ) remained unchanged as compared with baseline. After 10 years, isometric knee extensor strength was reduced as compared with baseline. Right hand and left hand grip strength was unaffected as well as the upper leg local muscle endurance (fatigue index). As estimated from the superimposition of single twitches on isometric contractions, the estimated torque at maximal motor unit activation was unchanged during the 10 years of GH replacement.

\section{Muscle strength corrected for age and gender}

After correction for age and gender using observed/ predicted value ratios, there were sustained increases in all variables reflecting muscle performance except for isometric knee extensor strength, fatigue index, and average $10 \mathrm{~s}$ right hand grip strength (Table 4). At baseline, knee flexor strength was $87-95 \%$ of predicted values, knee extensor strength was $86-89 \%$ of predicted values, and handgrip strength was $78-81 \%$ of predicted values. At study end, knee flexor strength had increased to $108-113 \%$ of predicted values, knee

Table 2 The dose of GH during 10 years of GH substitution in 24 elderly patients with GH deficiency above 60 years of age and the effects of this treatment on serum insulin-like growth factor 1 (IGF1), IGF1 SDS, and body composition. All values are shown as the mean (S.D). The statistical analyses are based on a one-way ANOVA followed by Student-Newman-Keuls post-hoc test.

\begin{tabular}{|c|c|c|c|c|c|c|c|}
\hline & Baseline & 1 year & 3 years & 5 years & 7 years & 10 years & $\begin{array}{c}\boldsymbol{P} \text { value } \\
\text { (5-10 years) }\end{array}$ \\
\hline Number of patients & 24 & 24 & 24 & 21 & 19 & 17 & \\
\hline Dose of GH (mg/day) & $0.72(0.39)$ & $0.43(0.20)^{\ddagger}$ & $0.37(0.10)^{\ddagger}$ & $0.37(0.10)^{\ddagger}$ & $0.37(0.15)^{\ddagger}$ & $0.37(0.20)^{\ddagger}$ & NS \\
\hline Serum IGF1 $(\mu \mathrm{g} / \mathrm{l})$ & $87(54)$ & $245(123)^{\ddagger}$ & $228(103)^{\ddagger}$ & $200(98)^{\ddagger}$ & $208(98)^{\ddagger^{\prime}}$ & $170(83)^{\ddagger}$ & NS \\
\hline IGF1 SDS & $-1.10(1.08)$ & $2.05(2.40)^{\ddagger}$ & $1.64(2.20)^{\ddagger}$ & $1.17(2.06)^{\ddagger}$ & $1.33(1.76)^{\ddagger}$ & $1.17(1.52)^{\ddagger}$ & NS \\
\hline Body height $(\mathrm{cm})$ & $168.5(11.8)$ & $168.6(11.8)$ & $168.3(11.8)$ & $168.2(11.8)^{*}$ & $168.4(11.3)^{\star}$ & $168.4(11.3)^{\star}$ & NS \\
\hline Body weight (kg) & 75.1 (12.3) & 74.4 (12.3) & $75.0(12.3)$ & $74.4(11.8)$ & $75.6(12.7)$ & $73.6(12.3)^{\star}$ & NS \\
\hline $\operatorname{BMI}\left(\mathrm{kg} / \mathrm{m}^{2}\right)$ & $26.6(4.4)$ & $26.3(4.4)$ & $26.7(4.4)$ & $26.5(4.4)$ & $27.0(4.9)$ & $26.7(4.9)$ & NS \\
\hline \multicolumn{8}{|l|}{ DEXA } \\
\hline Body fat (kg) & $25.8(8.3)$ & $24.1(8.3)^{\dagger}$ & $24.1(8.8)^{\star}$ & $23.6(8.3)^{\dagger}$ & $24.2(9.8)^{*}$ & $23.2(8.3)^{\dagger}$ & NS \\
\hline Lean body mass $(\mathrm{kg})$ & $46.8(10.8)$ & $47.9(11.3)^{\dagger}$ & $48.2(11.8)^{\dagger}$ & $48.1(11.3)^{\star}$ & $48.0(11.6)^{*}$ & $47.6(12.2)^{\star}$ & NS \\
\hline \multicolumn{8}{|l|}{ Four-compartment model } \\
\hline Body fat $(\mathrm{kg})$ & $22.4(8.3)$ & $20.5(9.3)^{\star}$ & $21.1(9.8)$ & $21.0(9.3)$ & $21.0(9.3)$ & $20.7(8.8)^{\star}$ & NS \\
\hline Body cell mass (kg) & $25.3(5.9)$ & $26.4(6.9)^{\star}$ & $26.2(6.9)$ & $25.4(6.9)$ & $25.8(6.4)$ & $25.8(6.9)$ & NS \\
\hline TBK (mmol) & 3068 (745) & 3165 (828) & 3147 (813) & 3050 (975) & 3075 (740) & 3097 (794) & NS \\
\hline TBN $(\mathrm{kg})$ & $1.58(0.34)$ & $1.62(0.34)$ & $1.64(0.44)$ & $1.58(0.32)$ & $1.54(0.32)$ & $1.55(0.32)$ & NS \\
\hline
\end{tabular}

${ }^{\star} P<0.05 ;{ }^{\dagger} P<0.01 ;{ }^{\ddagger} P<0.001$ (versus baseline). NS, not significant. 
Table 3 Measurements of isometric and isokinetic strength in knee flexion and extension, hand-grip strength, and the fatigue index during 10 years of GH replacement in 24 elderly GH-deficient patients above 60 years of age. All values are shown as the mean (s.D). The statistical analyses are based on a one-way ANOVA followed by Student-Newman-Keuls post-hoc test.

\begin{tabular}{|c|c|c|c|c|c|c|c|}
\hline & Baseline & 1 year & 3 years & 5 years & 7 years & 10 years & $5-10$ years \\
\hline \multicolumn{8}{|l|}{ Knee flexion } \\
\hline Isometric $60^{\circ}(\mathrm{Nm})$ & $54.7(3.9)$ & $59.2(4.9)$ & $60.7(4.5)^{\star}$ & $58.8(4.5)^{\star}$ & $57.3(4.4)$ & $56.6(4.6)$ & NS \\
\hline Concentric 60\% $\mathrm{s}(\mathrm{Nm})$ & $57.2(4.3)$ & $60.8(4.4)$ & $59.4(4.4)$ & $57.9(4.8)$ & $54.7(4.5)$ & $52.6(4.5)$ & $<0.05$ \\
\hline Concentric $180^{\circ} / \mathrm{s}(\mathrm{Nm})$ & 40.9 (3.1) & 42.5 (3.3) & $41.4(3.2)$ & 38.7 (3.3) & $39.3(3.4)$ & 38.8 (3.3) & NS \\
\hline \multicolumn{8}{|l|}{ Knee extension } \\
\hline Isometric $60^{\circ}(\mathrm{Nm})$ & $136.3(9.6)$ & $135.4(10.5)$ & $134.1(10.4)$ & $131.7(9.4)$ & $126.8(8.8)$ & $125.0(8.2)^{\star}$ & NS \\
\hline Concentric $60^{\circ} / \mathrm{s}(\mathrm{Nm})$ & $109.9(7.2)$ & $113.2(7.4)$ & $110.7(7.7)$ & $109.3(7.5)$ & $108.4(7.7)$ & $105.9(7.1)$ & NS \\
\hline Concentric $180^{\circ} / \mathrm{s}(\mathrm{Nm})$ & $78.0(5.3)$ & $84.2(6.3)$ & $82.8(5.9)$ & $82.0(5.7)$ & $80.6(6.4)$ & $78.9(6.1)$ & NS \\
\hline \multicolumn{8}{|l|}{ Grip strength, right hand } \\
\hline Peak $(n)$ & $279.8(22.2)$ & $281.9(24.8)$ & $293.3(25.8)$ & $294.9(26.6)$ & $286.0(24.0)$ & $287.0(24.0)$ & NS \\
\hline Average $10 \mathrm{~s}(n)$ & $235.9(20.0)$ & $229.8(20.7)$ & $246.4(23.0)$ & $243.9(23.0)$ & $237.5(21.6)$ & $236.3(21.3)$ & NS \\
\hline \multicolumn{8}{|l|}{ Grip strength, left hand } \\
\hline Peak $(n)$ & $263.7(20.1)$ & $252.2(21.6)$ & $263.3(22.0)$ & $269.4(22.1)$ & $257.5(20.5)$ & $262.8(20.6)$ & NS \\
\hline Average $10 \mathrm{~s}(n)$ & $225.3(18.5)$ & $209.6(19.1)$ & $218.3(19.2)$ & $217.2(19.6)$ & $217.2(19.0)$ & $215.9(18.1)$ & NS \\
\hline $\begin{array}{l}\text { Fatigue index (\% reduction of } \\
\text { peak torque) }\end{array}$ & $38.6(3.0)$ & $40.1(2.0)$ & $39.0(2.4)$ & $40.1(2.5)$ & $38.3(2.7)$ & $36.7(2.8)$ & NS \\
\hline $\begin{array}{l}\text { Estimated torque at maximal } \\
\text { motor unit activation: knee } \\
\text { extension (\% of maximal } \\
\text { voluntary isometric torque) }\end{array}$ & $104.4(5.8)$ & $104.2(5.6)$ & $102.9(3.6)$ & $103.1(3.7)$ & $102.9(3.7)$ & $103.2(3.8)$ & NS \\
\hline
\end{tabular}

${ }^{\star} P<0.05$ (versus baseline).

extensor strength had increased to $95-118 \%$ of predicted values, and handgrip strength had increased to $87-93 \%$ of predicted values.

\section{Gender differences}

The dose of GH, both in mg/day (not shown) and adjusted for body weight (Fig. 1A), was higher in women at all times during the 10-year period. In spite of similar response to treatment in terms of IGF1 SDS (Fig. 1B), the changes in BF and LBM as measured using DEXA were more marked in men (Fig. 1C and D). Women had higher BMI throughout the study. Baseline muscle strength, also corrected for age and gender, was similar in men and women except for concentric $\left(60^{\circ} / \mathrm{s}\right)$ knee flexor strength, which was lower in women than in men $(P<0.05)$.

Men and women demonstrated a similar response in all variables reflecting muscle performance. Isometric $\left(60^{\circ}\right)$ knee flexor (Fig. 2A) and concentric knee extensor strength $\left(180^{\circ} / \mathrm{s}\right.$; Fig. $\left.2 \mathrm{~B}\right)$ increased to a similar extent in both genders. At study end, knee flexor strength had increased to $103-110 \%$ of predicted values in men and to $108-116 \%$ of predicted values in women, knee extensor strength had increased to $90-113 \%$ of predicted values in men and $98-124 \%$ of predicted

Table 4 Knee extensor strength, left hand grip strength, and the fatigue index, expressed as percentage of predicted values, during the 10 -year GH replacement therapy in $24 \mathrm{GH}$-deficient patients above 60 years of age. All values are shown as the mean (S.D). The statistical analyses are based on a one-way ANOVA followed by Student-Newman-Keuls post-hoc test.

\begin{tabular}{|c|c|c|c|c|c|c|c|}
\hline & Baseline & 1 year & 3 years & 5 years & 7 years & 10 years & $5-10$ years \\
\hline \multicolumn{8}{|l|}{ Knee flexion } \\
\hline Isometric $60^{\circ}(\%$ of pred $)$ & $87.0(3.9)$ & $92.7(5.2)^{\star}$ & $100.9(4.7)^{\ddagger}$ & $99.8(4.4)^{\ddagger}$ & $109.3(5.5)^{\ddagger}$ & $112.8(5.7)^{\ddagger}$ & $<0.01$ \\
\hline Concentric $60 \%$ s (\% of pred) & $97.0(4.1)$ & $104.8(4.0)$ & $108.3(5.0)^{*}$ & $106.1(4.7)^{\star}$ & $106.3(5.0)^{*}$ & $107.0(5.6)^{*}$ & NS \\
\hline Concentric $180^{\circ} / \mathrm{s}$ (\% of pred) & $94.8(4.2)$ & $100.7(4.6)$ & $105.3(6.3)$ & $99.1(6.0)$ & $104.9(7.4)$ & $107.8(7.4)^{\star}$ & NS \\
\hline \multicolumn{8}{|l|}{ Knee extension } \\
\hline Isometric $60^{\circ}(\%$ of pred) & $86.0(3.4)$ & $89.3(3.3)$ & $90.3(3.4)$ & $91.5(3.9)$ & $91.0(4.5)$ & $95.0(4.5)$ & NS \\
\hline Concentric $60 \%$ s (\% of pred) & $86.0(3.4)$ & $89.3(3.3)$ & $90.3(3.4)$ & $91.5(3.9)^{*}$ & $96.6(4.3)^{\ddagger}$ & $97.8(4.4)^{\ddagger}$ & $<0.01$ \\
\hline Concentric $180 \%$ s (\% of pred) & $88.5(4.0)$ & $95.4(4.5)$ & $98.7(4.1)^{\dagger}$ & $101.0(4.4)^{\ddagger}$ & $109.4(5.6)^{\ddagger}$ & $118.3(8.8)^{\ddagger}$ & $<0.001$ \\
\hline \multicolumn{8}{|l|}{ Grip strength, right hand } \\
\hline Peak ( $\%$ of pred) & $78.7(3.0)$ & $78.4(4.1)$ & $84.7(3.7)$ & $86.7(4.2)^{*}$ & $91.0(4.6)^{\ddagger}$ & $93.7(4.8)^{\ddagger}$ & $<0.05$ \\
\hline Average $10 \mathrm{~s}$ (\% of pred) & $74.4(3.3)$ & $72.7(4.3)$ & $79.7(4.3)$ & $81.0(4.9)$ & $94.0(9.1)^{\ddagger}$ & $86.3(5.3)$ & NS \\
\hline \multicolumn{8}{|l|}{ Grip strength, left hand } \\
\hline Peak ( $\%$ of pred) & $80.5(3.6)$ & $76.1(4.5)$ & $81.8(3.7)$ & $84.4(4.1)$ & $91.0(4.3)^{\ddagger}$ & $93.2(4.6)^{\ddagger}$ & $<0.001$ \\
\hline Average $10 \mathrm{~s}$ (\% of pred) & $77.5(3.7)$ & $72.2(4.7)$ & $78.1(3.9)$ & $79.2(4.4)$ & $85.0(4.8)^{\star}$ & $86.7(4.3)^{\dagger}$ & $<0.05$ \\
\hline \multicolumn{8}{|l|}{ Fatigue index } \\
\hline (\% of pred) & $94.4(7.0)$ & $98.2(4.1)$ & $95.9(5.1)$ & $97.7(5.4)$ & $97.8(7.3)$ & $93.8(7.3)$ & NS \\
\hline
\end{tabular}

${ }^{\star} P<0.05 ;{ }^{\dagger} P<0.01 ;{ }^{\ddagger} P<0.001$ (versus baseline). 


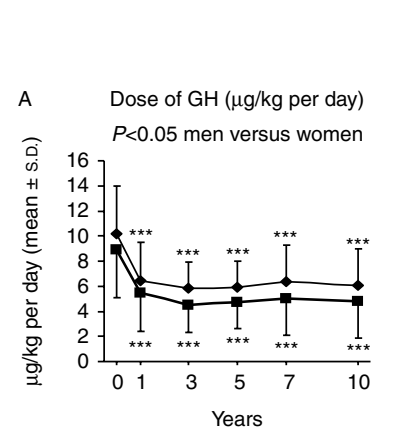

C $\quad$ Body fat $\quad P<0.05$ men versus women
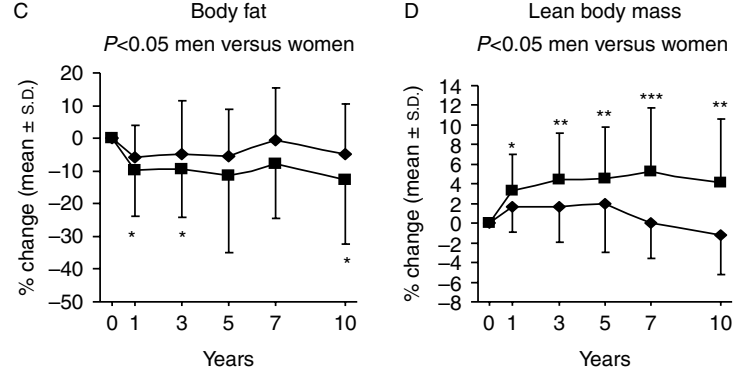

Figure 1 Dose of GH (A), IGF1 SDS (B), body fat (C), and lean body mass $(D)$ in men and women during 10 years of $\mathrm{GH}$ substitution in 24 elderly patients with GH deficiency of adulthood onset. The vertical bars indicate the S.D. for the mean values shown. The between-group $P$ value for IGF1 score is based on an analysis of the change from baseline, whereas that body fat and lean body mass are based on an analysis of the percentage change from baseline. Within-group $P$ values are based on an analysis of the absolute values. The shadowed area in (B) represents \pm 2 s.D. ${ }^{\star} P<0.05 ;{ }^{* \star} P<0.01 ;{ }^{* \star \star} P<0.001$ (versus baseline).

values in women, and handgrip strength had increased to $89-95 \%$ of predicted values in men and $84-93 \%$ of predicted values in women.

The estimated torque at maximal motor unit activation was similar in men and women at baseline

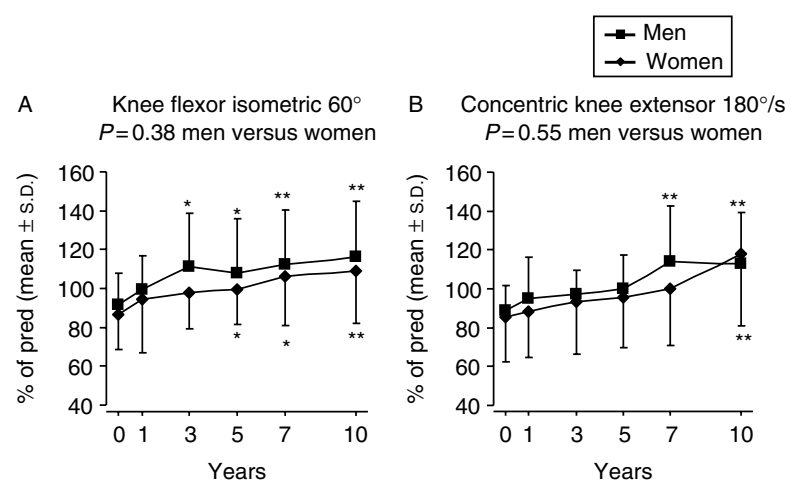

Figure 2 Observed/predicted (pred) value ratios for isometric $(60 \%$ s) knee flexor $(\mathrm{A})$ and concentric $(180 \% \mathrm{~s})$ knee extensor strength in men and women during 10 years of $\mathrm{GH}$ replacement in 24 elderly patients with GHD of adult onset. The vertical bars indicate the S.D. for the mean values shown. Between-group $P$ values are based on an analysis of the percentage change from baseline, whereas within-group $P$ values are based on an analysis of the absolute values. ${ }^{\star} P<0.05 ;{ }^{\star \star} P<0.01$ (versus baseline). (men 104.2 (6.6) versus women $104.6(5.3) \%$ of maximal voluntary isometric torque; $P=0.29$ ), and there was no significant difference in the treatment response $(P=0.89)$. However, at study end, men tended to have a higher estimated torque at maximal motor unit activation in relation to maximal voluntary torque (men 104.9 (2.9) versus women 101.6 (3.9) \% of maximal voluntary isometric torque; $P=0.056$ ). This means that at study end, women tended to activate a higher percentage of motor units at voluntary maximal muscle effort than men.

\section{Correlation analysis}

No correlation was found between the absolute baseline value and the percentage change at study end in the same muscle strength variable except for the fatigue index $(r=-0.62, P<0.01)$. After correction for age and sex using the observed/predicted value ratios, the baseline value of concentric knee flexor $\left(60^{\circ} / \mathrm{s}\right)$, concentric knee extensor $\left(180^{\circ} / \mathrm{s}\right)$, peak handgrip strength of right and left hands, and $10 \mathrm{~s}$ left hand grip strength correlated inversely with the percentage change at study end in the same variable $(r=-0.39$, $P<0.05 ; \quad r=-0.50, P<0.05 ; r=-0.47, P<0.05$; $r=-0.43, P<0.05$; and $r=-0.57, P<0.01$ respectively). This means that the patients with the lowest strength in these muscles at baseline had the greatest response to the 10-year GH replacement.

At baseline, serum IGF1 level was only positively correlated with isometric knee extensor muscle strength $(r=0.44, P<0.05)$. At study end, there was a inverse correlation between the percentage change in serum IGF1 concentration and the percentage change in isometric $\left(60^{\circ}\right)$ knee flexor and extensor strength, and isokinetic extensor $\left(60\right.$ and $\left.180^{\circ} / \mathrm{s}\right)$ muscle strength $(r=-0.50, P<0.05 ; r=-0.64, P<0.001$; $r=-0.49, P<0.05$; and $r=-0.46, P<0.05$ respectively). This means that the large increase in serum IGF 1 concentrations was not beneficial for augmentation in muscle strength in these patients. There was no correlation between the percentage change in LBM as measured using DEXA and the percentage change in any variable reflecting muscle function at study end. An inverse correlation between the percentage change in $\mathrm{BF}$ as measured using DEXA and the percentage change in average $10 \mathrm{~s}$ left hand grip strength $(r=-0.2$, $P<0.05)$ was noticed.

\section{Discussion}

This is one of the longest observational studies on the effects of $\mathrm{GH}$ replacement therapy on muscle performance in elderly hypopituitary patients. After 1 year, the GH replacement had increased mean IGF1 SDS to above +2 s.D. $(+2.05$ s.D.), but otherwise, mean IGF1 SDS was within the normal range. After 10 years, 
BF was reduced, and LBM was increased, as measured using DEXA. This is consistent with the lipolytic and anabolic effects of GH observed in previous studies $(4,10,23,24)$, demonstrating that a moderate dose of GH can induce a sustained improvement in body composition in elderly GHD adults.

GH replacement, as previously shown $(10,25)$, had a more marked effect on isometric knee flexor strength than on isokinetic knee flexor strength, possibly as a consequence of more reduced isometric strength in untreated GHD adults $(9,26)$. This allows to assume that increased muscle strength during GH replacement is not only due to increased muscle mass (27-29). In addition to increased muscle mass, possible qualitative anabolic intramuscular changes produced by the replacement with $\mathrm{GH}$ or other anterior pituitary hormones, or changes in physical activity or motor unit activation, could also affect muscle strength. In some support of this hypothesis, there was no correlation between the percentage change in LBM as measured using DEXA and the percentage change in any variable reflecting muscle function at study end.

In a previous study, we observed a more marked response in muscle performance following the 10-year $\mathrm{GH}$ replacement in patients below 50 years of age compared to patients older than 50 years (10). In the present study, we therefore investigated whether the 10-year GH replacement could affect muscle strength in elderly adults with GHD above 60 years of age. In terms of absolute values, the effect of GH replacement was small with a transient increase in isometric knee flexor strength and even a decrease in isometric knee extensor strength at study end. However, in the background elderly population, a $16 \%$ reduction in muscle strength could be anticipated over a 10-year period (2). After adjustment for age and gender using observed/predicted value ratios, sustained increases were observed in all variables reflecting muscle performance, except for isometric knee extensor strength $\left(60^{\circ}\right)$ and the fatigue index. At study end, knee flexor and extensor strength was normalized (increased to 108-113 and to 95-118\% of predicted values respectively), and hand grip strength nearly normalized (increased to $87-93 \%$ of predicted values). This suggests that the 10-year GH replacement can affect muscle performance also in elderly patients with GHD by protecting them from most of the age-related decline in muscle strength.

Correlation analysis displayed that the age- and sexadjusted baseline values of concentric knee flexor strength $(60 \%)$, concentric knee extensor strength $(180 \%$ s), and handgrip strength of both hands correlated inversely with the percentage change at study end in the same variable. Although it cannot be excluded that these findings are due to regression to the mean, these results suggest that the patients with the lowest baseline muscle strength had the most beneficial response to the 10-year GH replacement. The development of age-related sarcopenia could therefore be mitigated in these patients, and this is the major finding of this study.

Age-related muscle wasting may be associated with the loss of myonuclei through an apoptosis-like mechanism (30). To investigate neuromuscular function, superimposed single-twitch electrical stimulations were performed. The level of activation of motor units at voluntary maximal muscle effort was found to be unaltered during the 10 years of $\mathrm{GH}$ replacement. This study did not include a placebo group, but it has been suggested that the voluntary motor unit activation decrease with increasing age (31). The present results may therefore indicate that $\mathrm{GH}$ replacement provides protection from the age-related decline in motor neuron activation in elderly GHD adults, and that could be an underlying mechanism why $\mathrm{GH}$ replacement protects for most of the age-related decline in muscle strength in these patients.

The local isokinetic muscular endurance, expressed as fatigue index, remained unchanged, being 94\% of predicted values both at study start and study end, as previously shown in younger patients with GHD (10). In healthy elderly subjects, the fatigue index showed little difference between age groups (2), and there was no relationship between activity level and muscle endurance (2). It could therefore be hypothesized that the local muscular isokinetic endurance only to a small extent depends on GH-IGF1 status.

Serum IGF1 level was positively correlated with isometric knee extensor muscle strength at baseline, suggesting that circulating IGF1 is of some importance for muscle strength in elderly GHD patients. However, an inverse relationship was noticed between the percentage change in serum IGF1 concentration and the percentage change in isometric and isokinetic extensor muscle strength in elderly GHD patients. These correlations could indicate that some of the elderly patients received a too high dose of $\mathrm{GH}$, although the mean doses given were moderate. Furthermore, age- and sex-adjusted muscle strength remained increased also after the first 3 years of treatment, when the dosage of $\mathrm{GH}$ was essentially reduced. This further supports the notion that low $\mathrm{GH}$ dosage is preferable in elderly adults as this reduces the frequency of side effects like muscle pain and arthralgia.

As observed previously $(4,10)$, women normalized muscle strength to a similar extent as men, although the responses to $\mathrm{GH}$ replacement in terms of $\mathrm{BF}$ and LBM were more marked in men. In terms of neuromuscular function, women tended to activate a higher percentage of motor units at voluntary maximal muscle effort at study end $(P=0.056$ versus men). Higher voluntary motor unit activation in women could therefore be one explanation for the similar responses in muscle strength in both genders in spite of lower LBM increase in women.

In several studies, GH therapy increased LBM in older GH-sufficient individuals $(32,33)$. The effects of $\mathrm{GH}$ on absolute values of muscle strength and physical 
performance in healthy elderly subjects are, however, less obvious with no or only a minimal increase in strength in response to $\mathrm{GH}(34-36)$. It is not clear whether the effects of GH replacement in elderly GHD patients can anyhow predict the responsiveness of GH-sufficient elderly patients to GH. However, based on the present results, it could be speculated that $\mathrm{GH}$ treatment in elderly patients will not increase absolute muscle strength, whereas $\mathrm{GH}$ therapy may provide some protection from the age-related decline in muscle strength.

Weaknesses of the study are the relatively small size of the study population and that it is uncontrolled. However, the use of population-based, normative values for muscle performance (2) may to some extent compensate for the lack of a placebo group. Furthermore, we cannot exclude the possibility that replacement therapy with hormones other than GH, such as thyroid hormone and gonadal steroids, could have contributed to the increased muscle strength. Finally, the activity level of the patients was not measured. Therefore, a possible increase in physical activity in the GHD adults could have contributed to the increase in muscle strength.

In conclusion, the 10-year GH replacement in GHD elderly adults initially increased isometric flexor strength and subsequently protected against most of the normal age-related decline in muscle strength. A possible mechanism underlying this protective effect of $\mathrm{GH}$ may be that $\mathrm{GH}$ replacement appeared to counteract the age-related reduction in voluntary motor unit activation. In both genders, after correction for the age-related decline in muscle strength, the $\mathrm{GH}$ replacement normalized knee flexor and extensor strength, and almost normalized handgrip strength.

\section{Declaration of interest}

The authors declare that there is no conflict of interest that could be perceived as prejudicing the impartiality of the research reported.

\section{Funding}

This research did not receive any specific grant from any funding agency in the public, commercial or not-for-profit sector.

\section{Acknowledgements}

We are indebted to Marita Hedberg at the Department of Rehabilitation Medicine and to Lena Wirén, Ingrid Hansson, and Sigrid Lindstrand at the Research Center for Endocrinology and Metabolism for their skilful technical support.

\section{References}

1 Toogood AA \& Shalet SM. Growth hormone replacement therapy in the elderly with hypothalamic-pituitary disease: a dose-finding study. Journal of Clinical Endocrinology and Metabolism $1999 \mathbf{8 4}$ 131-136.
2 Sunnerhagen K, Hedberg M, Henning G-B, Cider A \& Svantesson U. Muscle performance in an urban population sample of 40- to 79-year-old men and women. Scandinavian Journal of Rehabilitation Medicine 200032 159-167.

3 Sartorio A \& Narici MV. Growth hormone (GH) treatment in GH-deficient adults: effects on muscle size, strength and neural activation. Clinical Physiology 199414 527-537.

4 Gotherstrom G, Bengtsson BA, Sunnerhagen KS, Johannsson G \& Svensson J. The effects of five-year growth hormone replacement therapy on muscle strength in elderly hypopituitary patients. Clinical Endocrinology 200562 105-113.

5 Lamberts S, Van ben Beld A \& Van der Lely A-J. The endocrinology of aging. Science $1997 \mathbf{2 7 8} 419-424$.

6 Metter E, Talbot LA, Schrager M \& Conwit R. Skeletal muscle strength as a predictor of all-cause mortality in healthy men. Journals of Gerontology. Series A, Biological Sciences and Medical Sciences 200257 359-365.

7 Cuneo R, Salomon F, Wiles C, Hesp R \& Sonksen P. Growth hormone treatment in growth hormone-deficient adults. I. Effects on muscle mass and strength. Journal of Applied Physiology 1991 70 688-694.

8 Jorgensen JO, Thuesen L, Muller J, Ovesen P, Skakkebaek NE \& Christiansen JS. Three years of growth hormone treatment in growth hormone-deficient adults: near normalization of body composition and physical performance. European Journal of Endocrinology 1994130 224-228.

9 Johannsson G, Grimby G, Sunnerhagen KS \& Bengtsson BA. Two years of growth hormone $(\mathrm{GH})$ treatment increase isometric and isokinetic muscle strength in GH-deficient adults. Journal of Clinical Endocrinology and Metabolism 199782 2877-2884.

10 Götherström G, Stibrandt-Sunnerhagen K, Bengtsson B-Å, Johannsson G \& Svensson J. Ten years of growth hormone (GH) replacement normalizes muscle strength in GH-deficient adults. Journal of Clinical Endocrinology and Metabolism 200994 809-816.

11 Johannsson G, Rosén T \& Bengtsson B-Å. Individualized dose titration of growth hormone $(\mathrm{GH})$ during $\mathrm{GH}$ replacement in hypopituitary adults. Clinical Endocrinology 199747 571-581.

12 Mazess R, Barden H, Bisek J \& Hanson J. Dual-energy X-ray absorptiometry for total-body and regional bone-mineral and softtissue composition. American Journal of Clinical Nutrition 199051 1106-1112.

13 Bruce Å, Andersson M, Arvidsson B \& Isaksson B. Body composition. Prediction of normal body potassium, body water and body fat in adults on the basis of body height, body weight and age. Scandinavian Journal of Clinical and Laboratory Investigation $198040461-473$.

14 Vartsky D, Elis K \& Cohn S. In vivo quantification of body nitrogen by neutron capture prompt gamma-ray analysis. Journal of Nuclear Medicine 197920 1158-1165.

15 Larsson L, Alpsten M \& Mattsson S. In-vivo analysis of nitrogen using a ${ }^{252} \mathrm{Cf}$ source. Journal of Radioanalytical and Nuclear Chemistry 1987114 181-185.

16 Aniasson A, Grimby G \& Rundgren Å. Isometric and isokinetic quadriceps muscle strength in 70-year-old men and women. Scandinavian Journal of Rehabilitation Medicine 198012 161-168.

17 Nordensköld U \& Grimby G. Grip force in patients with rheumatoid arthritis and fibromyalgia and in healthy subjects. A study with Grippit instrument. Scandinavian Journal of Rheumatology 199322 $14-19$.

18 Thorstensson A \& Karlsson J. Fatigability and fibre composition of human skeletal muscle. Acta Physiologica Scandinavica 197698 318-322.

19 Rutherford O, Jones DA \& Newhan DJ. Clinical and experimental application of the percutaneous twitch superimposition technique for the study of human muscle activation. Journal of Neurology, Neurosurgery, and Psychiatry 198649 1288-1291.

20 Thomeé R, Svantesson U \& Österberg U. Quadriceps muscle performance in sitting and standing in young women with patellofemoral pain syndrome and healthy women. Scandinavian Journal of Medicine E Science in Sports 19966 233-241. 
21 Landin-Wilhelmsen K, Wilhelmsen L, Lappas G, Rosén T, Lindstedt G, Lundberg P-A \& Bengtsson B-Å. Serum insulin-like growth factor $\mathrm{I}$ in a random population sample of men and women: relation to age, sex, smoking habits, coffee consumption and physical activity, blood pressure and concentrations of plasma lipids, fibrinogen, parathyroid hormone and osteocalcin. Clinical Endocrinology 199441 351-357.

22 Svensson J, Johannsson G \& Bengtsson B-A․ Insulin-like growth factor-I in growth hormone-deficient adults: relationship to population-based normal values, body composition and insulin tolerance test. Clinical Endocrinology $1997 \mathbf{4 6} 579-586$.

23 Gibney J, Wallace JD, Spinks T, Schnorr L, Ranicar A, Cuneo RC, Lockhart S, Burnand KG, Salomon F, Sonksen PH \& RussellJones D. The effects of 10 years of recombinant human growth hormone $(\mathrm{GH})$ in adult GH-deficient patients. Journal of Clinical Endocrinology and Metabolism $1999842596-2602$.

24 Fernholm R, Bramnert M, Hagg E, Hilding A, Baylink DJ, Mohan S \& Thoren M. Growth hormone replacement therapy improves body composition and increases bone metabolism in elderly patients with pituitary disease. Journal of Clinical Endocrinology and Metabolism $2000 \mathbf{8 5} 4104-4112$.

25 Jørgensen JO, Vahl N, Hansen TB, Thuesen L, Hagen C \& Christiansen JS. Growth hormone versus placebo treatment for one year in growth hormone deficient adults: increase in exercise capacity and normalization of body composition. Clinical Endocrinology 1996 45 681-688.

26 Cuneo RC, Salomon F, Wiles CM \& Sonksen PH. Skeletal muscle performance in adults with growth hormone deficiency. Hormone Research 199033 (Supplement 4) 55-60.

27 Janssen Y, Doornbos J \& Roelfsema F. Changes in muscle volume, strength, and bioenergetics during recombinant human growth hormone $(\mathrm{GH})$ therapy in adults with $\mathrm{GH}$ deficiency. Journal of Clinical Endocrinology and Metabolism $199984279-284$.

28 Rutherford OM, Beshyah SA, Schott J, Watkins Y \& Johnston DG. Contractile properties of the quadriceps muscle in growth hormone-deficient hypopituitary adults. Clinical Science $1995 \mathbf{8 8}$ 67-71.
29 Daugaard J, Bramnert M, Manhem P, Endre T, Groop L, Lofman M \& Richter E. Effect of 6 months of GH replacement on myosin heavy chain composition in GH-deficient patients. European Journal of Endocrinology $1999 \mathbf{1 4 1} 342-349$.

30 Marzetti E \& Leeuwenburgh C. Skeletal muscle apoptosis, sarcopenia and frailty at old age. Experimental Gerontology 2006 41 1234-1238.

31 Miller M, Holmback AM, Downham D \& Lexell J. Voluntary activation and central activation failure in the knee extensors in young women and men. Scandinavian Journal of Medicine $\mathcal{E}$ Science in Sports 200616 274-281.

32 Rudman D, Feller A \& Nagraj H. Effects of human growth hormone in men over 60 years old. New England Journal of Medicine 1990 $3231-6$.

33 Harman SM \& Blackman MR. Use of growth hormone for prevention or treatment of effects of aging. Journals of Gerontology. Series A, Biological Sciences and Medical Sciences 200459 652-658.

34 Taaffe D, Pruitt L, Reim J, Hintz R, Butterfield G, Hoffman A \& Marcus R. Effect of recombinant growth hormone on the muscle strength response to resistance exercise in elderly men. Journal of Clinical Endocrinology and Metabolism 199479 1361-1366.

35 Papadakis M, Grady D, Black D, Tierney M, Gooding G, Schambelan M \& Grunfeld C. Growth hormone replacement in healthy older men improves body composition but not functional ability. Annals of Internal Medicine 1996124 708-716.

36 Giannoulis MG, Jackson N, Shojaee-Moradie F, Nair KS, Sonksen PH, Martin FC \& Umpleby AM. The effects of growth hormone and/or testosterone on whole body protein kinetics and skeletal muscle gene expression in healthy elderly men: a randomized controlled trial. Journal of Clinical Endocrinology and Metabolism 200893 3066-3074.

Received 4 May 2010

Accepted 12 May 2010 